\title{
Contribuições da Hipnose para a Pesquisa Qualitativa
}

\author{
Maurício S. Neubern - Universidade de Brasilia, Brasilia, Brasil
}

\begin{abstract}
Resumo
O presente trabalho visa destacar algumas contribuições da hipnose para a pesquisa qualitativa, sobretudo em Psicologia. Tomando por base o pensamento complexo, ressalta a hipnose como um processo ao mesmo tempo ligado à comunicação analógica e a um conjunto de alterações que caracterizam a experiência de transe, como as alterações das referências eu-mundo e a emergência de processos inconscientes. Em sua conclusão, aponta importantes contribuições para a pesquisa qualitativa, no tocante à subjetividade do pesquisador, à reflexividade sobre o contexto de relação e à experiência do sujeito.

Palavras-chave: hipnose, pesquisa qualitativa, subjetividade
\end{abstract}

Hypnosis Contributions to Qualitative Research

\begin{abstract}
This paper aims to highlight some contributions of hypnosis to qualitative research, especially in psychology. Based on the complex thinking, the article conceives hypnosis as a process both connected to the analogous communication and to a set of changes that characterize the trance experience, such as changes in self-world references and the emergence of unconscious processes. In its conclusion, this work points out important contributions to qualitative research regarding the subjectivity of the researcher, the reflectivity of the context of relationship, and to the subject's experience.

Keywords: Hypnosis; Qualitative Research; Subjectivity; Subject.
\end{abstract}

Contribución de la Hipnosis a la Investigación Cualitativa

\begin{abstract}
Resumen
Este artículo tiene como objetivo destacar algunas de las contribuciones de la hipnosis a la investigación cualitativa, especialmente en Psicología. Sobre la base del pensamiento complejo, se enfatiza la hipnosis como un proceso al mismo tiempo ligado a la comunicación analógica y a un conjunto de alteraciones que caracterizan la experiencia de trance, como las alteraciones de las referencias yo-mundo y la emergencia de procesos inconscientes. Al concluir el artículo señala importantes contribuciones a la investigación cualitativa con respecto a la subjetividad del investigador, la capacidad de reflexión sobre el contexto de relación y la experiencia del sujeto.

Palabras-clave: Hipnosis; Investigación Cualitativa; Subjetividad
\end{abstract}

Hipnose e pesquisa qualitativa, em suas variadas expressões, apresentam importantes pontos em comum, particularmente no que diz respeito à inclusão de noções marginalizadas no projeto moderno de ciência (Santos, 2000; Stengers, 2001a) em suas propostas de conhecimento. Ambas referem-se ao dilema entre construir e revelar a realidade (Clandinin, 2013; Erickson, 1967; Stengers, 2001a); tanto uma como a outra implicam dimensões importantes da subjetividade do pesquisador (Arino, 2007; Stengers, 2001b; Sardan, 2015); elas também enfatizam processos ligados à comunicação, à reflexividade e ao contexto relacional (Bioy, 2008; Creswell, 2013; Denzin \& Lincoln, 2006; Erickson, 1986; Kim, 2015; Lévy, 1997; Roustang, 2015; Santos, 2000) como ainda tocam questões referentes à subjetividade da experiência dos sujeitos (Baud \& Midol, 2009; Gonzalez Rey, 2005; Neubern, 2014). Desse modo, a despeito da grande ênfase quantitativa das pesquisas contemporâneas, na qual a hipnose é basicamente avaliada em sua eficácia técnica (Dillworth \& Jansen, 2010; Jensen \& Patterson, 2014), a pertinência clínica e epistemológica das questões que levanta é muito mais próxima das propostas qualitativas de pesquisa.

Nesse sentido, em função da especificidade dos processos que a constituem, seja na comunicação analógica que lhe caracteriza (Erickson \& Rossi, 1979; Morin, 2001), seja no tocante aos estados de transe (Baud \& Midol, 2009; Neubern, 2014), a hipnose pode trazer contribuições significativas para questões importantes da pesquisa qualitativa. Isso porque o problema da influência presente na relação hipnótica (Roustang, 2015; Stengers, 2001b), em suas possibilidades de induzir a emergência de processos ou fabricá-los, traz à tona a questão da realidade construída na pesquisa junto ao outro, com seus problemas epistemológicos e éticos, sobretudo no que diz respeito à participação do pesquisador. Até que ponto a experiência de mundo do pesquisador (perpassada por suas filiações acadêmicas e socioculturais, suas crenças, ideologias, modos de pensar, sentir e agir) favorece uma condição de sujeito ou de indivíduo a seu interlocutor ou proporciona uma 
condição em que seja possível separar a construção legítima da manipulação de informações consiste numa questão de interesse de diferentes pesquisadores qualitativos (Creswell, 2013; Hennik, Hutter \& Bailey, 2011; Kim, 2015; Riessman, 2008; Sardan, 2015).

Ao mesmo tempo, a polifonia presente no transe (Augras, 2008; Baud \& Midol, 2009; Neubern, 2014), atravessado por várias vozes e instâncias além do controle do "eu" consciente também implicam questões importantes para a pesquisa qualitativa. Isso porque a emergência, típica do transe, de diferentes vozes toca em questões de grande pertinência para os pesquisadores contemporâneos (Elliot \& Lemert, 2009; Gonzalez Rey, 2005; Hall, 2014), como a heterogeneidade e múltipla determinação da subjetividade, que rompe com a noção de um "eu" homogêneo e as relações entre o individual e o coletivo.

Desse modo, o presente trabalho possui como objetivo destacar as contribuições específicas da hipnose para a pesquisa qualitativa em três questões distintas, mas profundamente integradas: a subjetividade do pesquisador; os processos reflexivos sobre o contexto relacional e a experiência do sujeito. Para tanto, tal discussão será desenvolvida a partir da noção de hipnose (Neubern, 2012a, 2012b, 2013a, 2013b, 2014) que envolve, numa perspectiva complexa (Morin, 1996, 2001, 2015), a integração entre formas analógicas da relação hipnótica e uma experiência de transe altamente polifônica. As formas analógicas referem-se a usos de linguagem específicos, contos de histórias, metáforas, analogias, jogos de palavras (Erickson \& Rossi, 1979), como também papéis dramáticos assumidos na relação com o sujeito (Neubern, 2012a) e possuem uma pluralidade de significados que são veiculados ao sujeito na construção do processo de transe.

Já a experiência de transe refere-se a um conjunto de processos nos quais as referências eu-mundo (tempo, espaço, causa, matéria e outro) são alteradas e uma série de processos inconscientes emergem no cenário subjetivo do sujeito (Neubern, 2013b, 2014). Na medida em que essas alterações ocorrem, o sujeito pode se ver em dois ou mais lugares simultâneos, viver diferentes experiências de tempo de uma só vez e experimentar uma materialidade vivida diferente da habitual, onde pode, por exemplo, sentir-se em pleno voo ou diluindo-se tranquilamente dentro de um rio. Esse processo coincide com a emergência de uma série de instâncias em larga medida autônomas com relação ao "eu" (Morin, 1996, 2001): o sujeito pode se deparar com uma cena familiar significativa referente a um "nós" familiar, em que ele recebe a ação dos outros, situando-se como um "mim"; a uma pessoa importante de seu passado com quem possui questões pendentes, um "ele" ou um "tu"; ao desencadeamento de processos somáticos de seu corpo, um "isso", ou ainda lidar com a aparição de seres espirituais (anjos, espíritos, daimons, deuses, orixás) que geralmente implicam em temáticas de um pertencimento cultural, portanto, um "nós". Tais instâncias, configuradas simbólica e emocionalmente na subjetividade, possuem certa condição de autonomia e agência e se consistem em referências diversas para a relação do sujeito consigo mesmo, com os outros e o mundo (Morin, 1996; 2001).

Duas advertências fazem-se necessárias no tocante ao desenvolvimento deste trabalho. Em primeiro lugar, ressalta-se que, na próxima sessão, será conferida maior ênfase aos autores e argumentos que sustentam as contribuições da hipnose em torno dos temas a subjetividade do pesquisador, a reflexividade no contexto e a experiência do sujeito, enquanto, na parte conclusiva serão destacadas as relações dessas ideias com importantes questões e autores da pesquisa qualitativa. Optou-se por tal organização com o intuito de se evitar a confusão entre autores e ideias de diferentes campos, principalmente devido às semelhanças que existem entre muitos deles. Em segundo lugar, destaca-se que a escolha dos autores qualitativos aqui efetivada não se centra sobre uma escola específica, mas sobre um conjunto de pesquisadores de diferentes abordagens teóricas (Arino, 2007; Clandinin, 2013; Creswell, 2013; Denzin \& Lincoln, 2006; Gonzalez Rey, 2005; Levy, 1997; Kim, 2015; Nathan, 2015; Riessman, 2008) que apresentam consideráveis afinidades no tocante a algumas questões centrais aqui desenvolvidas, como a construção da realidade, a subjetividade, a reflexividade e o sujeito. Embora tal escolha seja, em alguma medida, arbitrária, ela se fez necessária como foco para o desenvolvimento dos objetivos aqui propostos.

\section{O Pesquisador, o Contexto e o Sujeito}

A especificidade do transe hipnótico, com suas complexas e variadas subversões (Neubern, 2013a, 2014), remete a questões de grande relevância para a pesquisa qualitativa, apontando para diferentes necessidades a serem cumpridas pela construção de pensamento do pesquisador. Um primeiro ponto a ser destacado nesse sentido é o da subjetividade do pesquisador que possui especial papel na construção do processo de transe do sujeito, uma vez que suas produções subjetivas são constituintes dos processos de 
influência hipnótica que se concretizam na relação com o outro (Roustang, 2015).

O impacto comumente desorganizador do transe sobre o pesquisador pode variar desde a manifestações leves de sinais de transe em seu próprio corpo (movimentos involuntários na musculatura, alterações do foco visual e da respiração, visões e percepções não compartilhadas) à emergência de processos, cenas, personagens e seres (folclóricos, míticos e espirituais) ligados a seus nichos de pertencimento. Cenas do passado infantil na família, memórias de eventos e pessoas importantes, ideias e personagens teóricos, visões e possessões por orixás, santos, espíritos e deuses, podem aparecer de modo mais ou menos nítido, oferecendo a possibilidade de compreensão de suas influências nas configurações subjetivas ali presentes, com toda uma produção de sentidos, símbolos e emoções marcantes naquele jogo relacional. Trata-se de processos que comumente remetem a nichos culturais de pertencimento, filiações teóricas e ideológicas, compromissos, interesses e práticas institucionais, vinculações e missões familiares que, de certo modo, situam o pesquisador como seu representante diante de momentos da pesquisa significativos para ele.

Toda uma rede semiótica (Arino, 2007) pode se fazer acessível entre tais processos de sua subjetividade, ao mesmo tempo individual e coletiva, e aquilo que o pesquisador veicula ao sujeito em termos de sentimentos, como compaixão, medo, rejeição, empatia (Ribeiro, 2007), movimentos transferenciais, "como meu irmão", "o tio Walter", “o vizinho chato", "meu pai” (Ferro \& Basille, 2015), modos de uso de suais ideias, como teoria, doutrina ou tecnicismo (Morin, 2015) e os papéis por ele adotados frente ao outro, "materno", "rival", "filho", "professor", "boxeador" ou "colaborador" (Neubern, 2012a). Assim, embora a demarcação entre fabricação e revelação não seja nítida, nem simples de ser obtida na hipnose (Stengers, 2001a), tal perspectiva pode favorecer a qualificação da influência do pesquisador em seu processo de construção sobre o cenário do sujeito. À medida que compreende seu próprio campo de influência na construção da relação com o sujeito, ele pode estabelecer uma compreensão mais pertinente sobre as produções que emergem desse sujeito, enquanto processos próprios que não dependem totalmente dessa influência.

Semelhante campo de influência refere-se a uma rede sistêmica e polissêmica de signos (palavras, tons de voz, pausas, expressões, imagens, intenções, sentimentos) que são transmitidos ao sujeito num processo relacional (Neubern, 2013b, 2014). Além de uma influência mútua entre seus componentes semióticos, que favorece a construção criativa de outros processos, tal campo envolve também um poder de evocação não determinista de realidades junto ao outro. Esse campo de influência destaca um curioso paradoxo (Neubern, 2014), posto que o transe emerge a partir daquilo que é produzido nessa relação mútua (dependência), mas não faz do sujeito um autômato limitado à obediência de ordens externas, pois sua ação é altamente criativa, tendo como referências centrais experiências individuais e coletivas de seu mundo.

Nesse sentido, o que a participação da subjetividade do pesquisador na hipnose parece destacar como contribuição à pesquisa qualitativa pode ser sintetizado em dois tópicos. Primeiramente, há o destaque de uma série de dimensões de pertencimentos e afiliações que o habitam, que podem mesmo possui-lo e conduzi-lo e que, não raro, são confrontadas pela experiência do outro. Tais processos permitem considerar que a influência de um pesquisador não é gratuita ou neutra, mas parte de experiências que precisam ser levadas em conta e, por vezes, confrontadas pela diferença que vem por meio do mundo do outro, seja em termos éticos, seja em termos epistemológicos (Nathan, 2007). Em segundo lugar, o campo de influência se apresenta como uma condição importante para se qualificar a experiência do outro num processo de pesquisa, pois a subjetividade deste não é um objeto isolado e imune às trocas com o outro. O que emerge enquanto expressão subjetiva do outro, portanto, possui algo de sua criação autônoma, mas também se liga a processos específicos e maleáveis de troca que não se constituem como fontes de erro, mas elementos cruciais de um processo de pesquisa (Morin, 2015).

De outra parte, a segunda contribuição relevante da hipnose para a pesquisa qualitativa diz respeito à reflexividade quanto ao contexto em que se dá a relação entre o pesquisador e o sujeito (Neubern, 2012b). Face a uma série de registros que atravessam o contexto relacional, como culturais, econômicos, institucionais, políticos, sexuais, familiares, étnicos, espirituais, de classe, de gênero (Neubern, 2013b), o pesquisador se pergunta constantemente sobre qual deve ser o seu papel diante do sujeito e de quais condições este necessita para desenvolver suas construções durante a pesquisa. A dimensão analógica da comunicação que tem lugar entre os protagonistas (Morin, 2001) possui uma importância fundamental. Isso porque, quando o pesquisador se coloca num determinado papel 
(Neubern, 2012a) e elabora contos, metáforas, jogos de palavras e transgressões de linguagem (Erickson \& Rossi, 1979), há o oferecimento de uma pauta relacional ao sujeito, que nela pode se envolver por meio da polifonia que constitui sua subjetividade (Morin, 2001), mesmo que, entre tais instâncias, possam surgir contradições e conflitos.

Essa questão remete a importantes considerações sobre a reflexividade na relação com o sujeito. Primeiramente, de um ponto de vista técnico, a construção de semelhante contexto relacional precisa oferecer possibilidades diversas de criação, principalmente no tocante à emergência de processos além do controle consciente e deliberado do sujeito. A dimensão analógica aqui destacada é de grande relevância nesse sentido por oferecer possibilidades criativas que fogem à lógica dominante em muitas pesquisas atuais (Jensen \& Patterson, 2014) na qual uma sugestão visa obter uma determinada resposta: ela se refere, antes de tudo, a um espectro de possibilidades para as construções do sujeito, envolvendo determinada temática simbólica relevante para aquele momento particular (Erickson, 1967; Neubern, 2012a). As técnicas indutoras de uma pesquisa, portanto, necessitam possuir um caráter aberto, no sentido de oferecer múltiplas possibilidades de criação e espontaneidade e, em certa medida, analógico a fim de favorecer o acesso a dimensões contraditórias da subjetividade, nem sempre acessíveis por técnicas diretas de interrogação.

Em segundo lugar, semelhante contrato relacional necessita ir além da técnica de modo a propor, por meio das atitudes do pesquisador, uma profunda consideração ao outro enquanto sujeito singular. A princípio, o pesquisador nada deve saber, sob óticas e conceitos universais, de como as pessoas devem ser ou como devem ocorrer um processo terapêutico (Erickson, 1986; Roustang, 2015): cada pessoa deve ser acolhida no contexto relacional com suas próprias formas de pensar, gerar sentido, seus modos de relação, seus preconceitos, resistências e valores que podem mesmo vir a se transformar em importantes recursos para o desenvolvimento da hipnose. Como nada pode afirmar sobre o outro (Neubern, 2013a), o contexto permite que esse outro se mostre e se aproprie de seu próprio mundo num processo favorável para atender suas demandas.

Tal postura, a bem dizer a-teórica (Erickson, 1967, 1986), não significa a renúncia de qualquer modo de construção teórica sobre o outro, mas o reconhecimento que a hipnose proporciona de dois aspectos de grande importância para a pesquisa. Por um lado, o de que a experiência do outro não é passível de ser reduzida a uma teoria no sentido moderno do termo, o que exige uma mudança radical na concepção de teoria (Neubern, 2004); por outro, que as atitudes de acolhimento do pesquisador a este outro são transmitidas no processo relacional e precisam favorecer que ele se mostre a partir de suas próprias referências, e não em função de expectativas, teorias ou critérios prévios (Erickson, 1992).

Em terceiro lugar, tal perspectiva não consiste numa nova forma de universalização da relação com o sujeito, pois semelhante consideração com ele demanda a necessidade de um leque de modalidades de papeis como possíveis propostas relacionais. A aceitação endereçada ao outro não deve significar a universalização de uma data atitude, como a conversação dialógica (Clandinin, 2013; Kim, 2015), na qual o pesquisador assume o papel homogeneizado de facilitador ou mediador, uma vez que a polifonia presente na hipnose remete a uma variedade de papeis possíveis que nem sempre priorizam tal modo de relação (Clément, 2011; Nathan, 2015). O transe pode, portanto, favorecer a emergência de processos e modos de ser geralmente inibidos na vida cotidiana, mas que possuem uma importância fundamental para o sujeito e necessitam ser acolhidos em pautas relacionais específicas.

Temáticas, seres e processos geralmente longe do olhar social e ligados a sexo, agressividade, violência, dinheiro, legados familiares, vergonha, segredos, medo e espiritualidade (Clément, 2011) podem gerar considerável sofrimento junto ao sujeito, caso não sejam devidamente reconfiguradas em seu mundo e demandar pautas relacionais diversas para serem acolhidas. Ao invés da adoção de uma única forma relacional, os papeis de "professor", "colaborador", "tirano", "provocador", "mãe", "amigo", "lutador" e "sedutor" adotados pelo pesquisador, desde que resguardadas as devidas condições éticas, podem igualmente se constituir como atitudes facilitadoras do processo hipnótico desse sujeito, uma vez que sejam contempladas suas necessidades clínicas (Neubern, 2012a). Disso decorre que a diversidade de necessidades, modos de ser e de se relacionar dos sujeitos, podem demandar uma variedade de propostas relacionais que fogem a perspectivas standards de contextos de pesquisa, nas quais determinadas condições, instrumentos e técnicas são eleitos a partir de critérios que são pertinentes ao pesquisador e sua comunidade de pertencimento científico, mas não possuem qualquer consideração com a singularidade dos sujeitos. 
Por fim, a terceira grande contribuição da hipnose diz respeito ao caráter polifônico do cenário subjetivo do sujeito durante o transe. Isso porque, quando este mergulha na experiência hipnótica, e sua condição de "eu" cede lugar a uma pluralidade de instâncias ou vozes (Morin, 2001; Neubern, 2013a), o problema da compreensão de seus significados particulares ganha outros contornos. Aquilo que significa algo para o sujeito, portanto, pode adquirir sentidos muito diferentes em função da instância que se apresente em dado momento e de todo um jogo relacional que pode haver entre elas: os conflitos entre o "nós" familiar e o "eu" individual, a escravização deste por um "ele" de seu mundo, a negociação entre uma "ela" de seu passado e seu "eu" ainda na representação infantil. A hipnose possui uma radicalidade capaz de apresentar detalhes dessa pauta de interações e de como semelhante heterogeneidade de vozes e instâncias impacta as construções do sujeito num dado momento.

Semelhante perspectiva coloca problemas de pesquisa de grande relevância na medida em que o sujeito em transe, tradicionalmente associado a uma concepção individualista (Michaux, 2007), torna-se também, como um legítimo holograma (Morin, 2015) o palco de experiências e saberes coletivos (Nathan, 2015; Neubern, 2013a). Nesse sentido, o pesquisador se depara com o desafio teórico nem sempre bem-sucedido de preservar a importância clínica e epistemológica da categoria sujeito, com seus aspectos singulares, ativos e criativos (Gonzalez Rey, 2011; Lévy, 1997; Morin, 2001) sem isolá-la ou diluí-la em processos macrossociais, que ao mesmo tempo não podem ser restritos ao psicologismo típico de óticas individualistas. A expressão que significa algo para o sujeito, portanto, pode possuir vários desdobramentos e enraizamentos que perpassam e são configurados em sua individualidade, mas também se ligam irremediavelmente a diversos processos coletivos.

\section{Conclusão/Considerações Finais}

O impacto da comunicação analógica característica do transe (Neubern, 2012b; Morin, 2001) sobre a subjetividade do pesquisador merece consideração especial. Isso porque, embora seja possível conceber questões como a mobilização emocional e os conflitos de pertencimento por outras óticas e métodos (Arino, 2007; Devereux, 1980; Ferro \& Basille, 2015), o transe, não raro, proporciona experiências radicais que podem desestabilizar o lugar pretensamente blindado e seguro por meio do qual o pesquisador procura interpelar pessoas e grupos. Desse modo, assim como ele pode alterar as referências de "eu" e promover a emergência de processos inconscientes no sujeito, ele também pode perturbar a instrumentalidade teórica e metodológica do pesquisador que, por vezes, procuram lhe servir como formas de defesa racional frente ao mundo selvagem e cheio de perigos do outro. Embora nem sempre muito relatados e debatidos em pesquisas qualitativas, os casos de captura, possessão e surpresa de pesquisadores (Leiris $\left.{ }^{1}, 1980\right)$, não são incomuns e nem deixam de ser significativos para a compreensão da pesquisa.

Logo, quando o pesquisador, mesmo sem perceber, é capturado de modo mais ou menos intenso pelo transe, revê cenas e pessoas de sua própria infância, comove-se profundamente com o sofrimento do outro, reatualiza um evento traumático há muito escondido, visualiza, é interpelado ou até possuído por um ser espiritual, há uma espécie de confrontação epistemológica e teórica vinda desse mundo que precisa ser qualificada enquanto momento de pesquisa. Isto porque tal confrontação pode apontar para uma recusa ao modo pela qual é interpelada, para uma reação produtiva que leve o pesquisador a se pensar, em suma para uma oposição que o convide a mudanças importantes em suas próprias ideias e intenções (Nathan, 2007; Stengers, 2001b).

O transe pode levar o pesquisador a compreender que fenômenos sociais e subjetivos que parecem atacá-lo em pontos vitais de seu saber não significam a priori formas de resistência, sabotagem ou falta de cooperação, mas convites à reflexão sobre si mesmo e seu papel nesta pesquisa: ele pode aprender a questionar se suas ideais sobre o outro seriam representativas de tal universo, se suas propostas de abordagem são pertinentes a ele, numa palavra, se se porta como sujeito ou escravo de um dado pensamento teórico. A noção de algo além da consciência que tal problemática evoca, se aplicada ao pesquisador, traz grandes perspectivas de reflexão nesse sentido por ressaltar uma diversidade de ligações subjetivas (heranças familiares, pertencimentos culturais, valores sociais) e profissionais (a grupos, sistemas teóricos, comunidades, instituições e o próprio contexto social) que o precedem e influenciam sem que, muitas vezes, ele mesmo delas se perceba. Em suma, a hipnose coloca em questão o pesquisador, ensinando-o que, para se referir ao outro, ele necessita também

\footnotetext{
${ }^{1}$ Michel Leiris (1980) é um dos poucos autores que relata e debate uma experiência pessoal, quando, estudando aspectos teatrais do transe no Congo, apaixonou-se por uma jovem que realizava tais performances. Esse problema é relatado com mais frequência na Antropologia do que em outras ciências humanas.
} 
permitir-se a esse confronto que o faça se referir a seu lugar, a sua condição de sujeito, a suas filiações e à pertinência de suas ideias.

Outra contribuição digna de nota destacada pela hipnose é a concepção da subjetividade do pesquisador enquanto campo de influência que permite a emergência das construções do sujeito. A perspectiva de campo que a hipnose traz à tona vai muito além de uma dimensão puramente técnica, uma vez que envolve, na trama relacional, uma rede de formas e signos polissêmicos, geralmente analógicos, emocionais, simbólicos, perceptivos e vitais com múltiplas possibilidades emergentes e considerável poder de evocação de realidades junto ao outro (Neubern, 2012a, 2014).

A compreensão de semelhante rede e seu nada desprezível poder de criar ou fazer emergir realidades junto ao sujeito consiste num momento importante de compreensão sobre a qualidade das informações e processos que este produz, que além do dilema entre farsa, manipulação e legitimidade, remete também a questões de ordem contextual muito além da intencionalidade dos protagonistas. O estudo desse campo de influência presente nos processos hipnóticos, que também envolve a participação do sujeito, pode ser de grande relevância para as discussões atuais sobre campo (Ferro \& Basille, 2015; Ribeiro, 2007), como sobre o problema ontológico dos processos subjetivos (Gonzalez Rey, 2003, 2005; Sardan, 2015), que nem sempre merecem a atenção dos pesquisadores de diferentes ciências humanas e sociais, malgrado tenha sido destacado há muito por Kurt Lewin (1951/1964). A noção de campo remete, portanto, a um problema qualitativo e complexo (Morin, 1996, 2001) em que uma influência mútua e polissêmica da relação (dependência) oferece condições para emergência de uma dada realidade subjetiva junto ao sujeito (autonomia).

Já no que se refere à reflexividade quanto ao contexto, a hipnose traz considerações significativas principalmente no que diz respeito ao lugar que é oferecido ao sujeito no contexto da pesquisa, o que possui importantes implicações. Em primeiro lugar, quando se assume a dimensão de influência tão destacada pela hipnose (Neubern, 2012b; Roustang, 2015), não se enfatiza apenas o aspecto relacional, mas o teor construtivo das condições relacionais nas quais o sujeito é situado, ou seja, em que realidade que ele é convidado a participar na referida pesquisa. Tal como destacado por outros autores (Creswell, 2013; Riessman, 2008; Sardan, 2015), os procedimentos técnicos utilizados na pesquisa podem favorecer a construção de um contexto que situe a pessoa em diferentes condições: ele pode ser um indivíduo que apenas forneça respostas, um autômato que reproduza o que dele se espera ou um sujeito que construa suas informações de modo criativo, uma vez que sente que seu mundo (inclusive suas motivações e necessidades) foi aceito e considerado nessa relação.

Contudo, na medida em que foca aspectos analógicos que evocam processos além das deliberações do "eu", a hipnose destaca a importância do teor espontâneo na criação do sujeito que, frequentemente, subverte as expectativas do pesquisador. Tais informações remetem a uma noção nem sempre contemplada nas pesquisas contemporâneas, segundo a qual os sistemas e processos de mundo da experiência não se organizam de modo mecânico, mas em processos diferenciados de agenciamento (Gallahger, 2012), ou seja, uma espécie de inteligência organizacional que vela pela integridade e as necessidades do sistema.

Embora o tema ainda mereça muitos aprofundamentos, a hipnose abre campo a reflexões significativas a seu respeito, principalmente ao destacar como diferentes processos, como as instâncias subjetivas, parecem estabelecer uma comunicação muito próxima com o pesquisador por meio das sugestões. Tal discussão pode ser de grande relevância para a compreensão da subjetividade na pesquisa, sobretudo no tocante a aspectos que envolvem a espontaneidade, a contradição e a criação que, por vezes, podem fornecer indicadores pertinentes ao pesquisador, principalmente quando tais informações escapam à intenção do sujeito (Gonzalez Rey, 2005).

Em segundo lugar, a reflexividade promovida pela hipnose traz ainda um desafio teórico ao pesquisador, na medida em que este precisa construir um pensamento para desenvolver sua pesquisa sem o impor ao sujeito. Nesse sentido, nada poder afirmar sobre o outro (Neubern, 2013a) significa que, num primeiro momento, o pesquisador necessita silenciar suas vozes teóricas para estabelecer um contrato relacional com esse sujeito, reconhecendo o completo desconhecimento sobre ele, mas, ao mesmo, tempo colocando-se disponível a conhecê-lo a partir de suas próprias perspectivas de mundo. Contudo, à medida que o processo de pesquisa avança, o pesquisador talvez possa afirmar algo sobre esse sujeito, mas considerando que tal afirmação se dá em função de um contrato relacional entre eles num determinado momento, o que faz de seu saber algo em certa medida partilhado, contextualizado e local, tal como também levantado por pesquisadores de outros campos (Clandinin, 2013; Kim, 2015; Santos, 2000). 
A hipnose, contudo, destaca que as tecnologias e saberes culturais envolvidos na experiência dos sujeitos (Neubern, 2013a), assim como sua consideração pessoal sobre o que vivencia, precisam ser acionadas para o questionamento daquilo que o pesquisador afirma, de modo a contribuir sobre a legitimidade e pertinência que tais afirmações pretendem ter sobre seu mundo. Isso não significa que o pesquisador deva se posicionar como um refém de seus sujeitos, mas apenas traz a questão sobre como leva em conta, em suas construções, a cosmovisão, configurada por influências individuais e coletivas, daqueles com quem estabelece um contrato relacional para sua pesquisa.

Logo, suas construções teóricas necessitam de uma flexibilidade e abertura ao mundo empírico muito diferente do preconizado por grande parte das perspectivas modernas (Neubern, 2004). A complexidade singular, partilhada e contextualizada de tais universos não se dobram a uma tentativa de apreensão, captura e controle de um pensamento unilateral que lhes interpela e se mostra intocável, mas a um processo de diálogo no qual possa se mostrar a partir de suas próprias referências e sentidos e promover perturbações produtivas em quem lhes interpela. É por tal razão que, ao invés de se propor uma postura literalmente teórica, concebe-se que tal construção seja flexível para acolher tais movimentos e articular suas informações sem a imposição de conteúdos prévios, como de certo modo concebem categorias como configurações (Gonzalez Rey, 2011; Neubern, 2013b), signos (Arino, 2007) e dispositivos (Nathan, 2007).

Em terceiro lugar, a reflexividade sobre o processo hipnótico também traz à tona o problema do papel exercido pelo pesquisador em sua relação com o sujeito. De certo modo, a noção de drama presente em Erickson (citado por Neubern, 2012a) ressalta que não existe um cenário relacional a priori a ser proposto pelo pesquisador, pois a diversidade de processos e modos de relação emergentes no transe demandam diferentes possibilidades relacionais. Quase como ao modo de um ator, ele precisa desenvolver formas dramáticas distintas para propor seu contexto relacional, em função dos modos de ser singulares dos sujeitos com quem venha a trabalhar (Erickson, 1986, 1992). Em suma, além de poder assumir diferentes papeis relacionais, o pesquisador também desenvolve diferentes estilos de linguagem e procedimentos técnicos, de modo a buscar coerência com as exigências do sujeito singular, por excelência, e do contexto, perpassado pelo momento, pelo acontecer e pelo incerto (Morin, 2015; Scheschner, 2013).
Tal problema coloca em questão uma tendência universalista também presente, mas nem sempre assumida, em muitas propostas de pesquisas qualitativas (Denzin \& Lincoln, 2006; Creswell, 2013), quando se determinam modos relacionais, instrumentos e expectativas prévias sobre o papel dos protagonistas. Desse modo, apesar das significativas contribuições, a conversação dialógica (Clandinin, 2013; Kim, 2015), a comunicação (Gonzalez Rey, 2005) e a própria reflexividade (Lévy, 1997) são alguns exemplos ilustrativos de condições idealistas e universais para o papel do sujeito e a proposta de relação a ser adotada.

A reflexividade sobre a hipnose traz ainda um problema ético no tocante aos impactos que um procedimento de pesquisa possui sobre o sujeito e seu mundo. Semelhante alteração de referências de "eu" (Neubern, 2014) podem implicar questões de organização profunda do sujeito, de modo a colocar em risco sua integridade. Desse modo, o contexto clínico de pesquisa necessita ser protegido, tal como destacado por Erickson (1986), de modo que o sujeito possa lidar com seus processos dentro de uma considerável margem de segurança, colocando-se minimamente possível em risco.

Daí o porquê de a pesquisa necessitar de uma avaliação processual e, por vezes, institucional (Nathan, 2007), na qual o sujeito e sua rede tenham voz ativa, no que diz respeito ao impacto de seus procedimentos sobre a autonomia e a integridade em diferentes níveis (afetiva, constitutiva, moral), de modo a se evitarem problemas iatrogênicos, como a desagregação psíquica, a colonização narrativa e a desconsideração de suas necessidades, referências simbólicas e valores. Isso porque, para que situações de abuso e violência sejam evitadas num contexto em que o considerável poder do pesquisador contrasta com uma condição geralmente vulnerável dos sujeitos (seja por perda de consciência ou exposição íntima), são necessários dispositivos técnicos, afetivos e institucionais que promovam a garantia de direitos de todos os que dela participam (Nathan, 2007, 2015).

Por fim, ao destacar a polifonia presente na constituição do sujeito, o transe aponta para importantes problemas de pesquisa. Isso porque, quando tais alterações ocorrem, embora o sujeito possa parecer temporariamente eclipsado (Clément, 2011), ele não é diluído face a um conjunto de outras instâncias, mas apenas se posiciona como testemunha mais ou menos ativa do processo corrente (Erickson, 1986; Neubern, 2014). O transe possui, portanto, uma possibilidade de 
destacar a subjetividade humana em seu caráter, simultaneamente, uno (no qual o sujeito parece se identificar com o "eu") e múltiplo, onde uma diversidade de instâncias e processos coletivos apontam para as articulações diversas entre coletividades que habitam um indivíduo e outro que também as constrói por suas ações (Morin, 2001).

Além de toda a necessidade já discutida por alguns autores sobre a dialética entre o sujeito e o mundo social (Elliot \& Lemert, 2009; Hall, 2014), o transe aponta para a necessidade de construção de categorias que precisem contemplar tanto a constituição dessas instâncias que se relacionam com o "eu" e possuem grande influência nos modos de relação do sujeito (Morin, 2001), como de processos e seres (espíritos, seres-ideias, deuses, daimons, anjos) que não se restringem a uma produção individual, mas remetem a todo um maquinário cultural e noosférico autônomo que, por vezes, podem até se impor aos sujeitos e dominá-los e possuí-los (Morin, 2015; Nathan, 2015; Neubern, 2013a).

Disso decorre que a fundamental questão sobre o que determinado tema ou expressão significa para o sujeito em sua singularidade (Arino, 2007; Creswell, 2013; Gonzalez Rey, 2011) não pode ser concebida numa ótica homogênea, de acordo com a lógica de um "eu", mesmo que este seja uma das principais referências para a unidade subjetiva. Ela remete a toda uma rede de processos e formas de relação (comércio, negociação, escravidão, amor, conflito) que podem se situar muito além desse "eu" entre instâncias e seres que o habitam e criam as realidades de seu mundo. O sentido desse tema, portanto, envia a pesquisa tanto a um caráter múltiplo e sistêmico de processos semióticos (símbolos, sentimentos, reações, imagens, memórias), como a uma diversidade de instâncias, seres (Nathan, 2015) e dimensões da subjetividade humana que ainda necessitam de maiores investigações.

\section{Referências}

Arino, M. (2007). La subjectivité du chercheur en sciences bumaines. Paris: l'Harmattan.

Augras, M. (2008). O duplo e a metamorfose. Petrópolis: Vozes.

Baud, S., \& Midol, N. (2009). La conscience dans tous ses états. Moulineaux: Masson.

Bioy, A. (2008). Iatrogénie et hypnose dans le champ de la douleur. Douleur et Analgésie, 21, 169-173. doi: 10.1007/s11724-008-0098-z
Clandinin, D. J. (2013). Engaging in narrative inquiry. New York: Left Coast Press.

Clément, C. (2011). L'appel de la transe. Paris: Stock.

Creswell, J. (2013). Qualitative inquiry and research design. London: Sage Publications.

Denzin, N., \& Lincoln, Y. (2006). O planejamento da pesquisa qualitativa. Teorias e abordagens. Porto Alegre: Artmed.

Devereux, G. (1980). De l'angoisse à la méthode. Paris: Flammarion.

Dillworth, T., \& Jensen, M. (2010). The role of suggestion in hypnosis for chronical pain: a review of the literature. Open Pain Journal, 3(1), 39-51. Recuperado de http://www.creativecommons.org/ licenses/by-nc/3.0/

Elliot, A., \& Lemert, C. (2009). The new individualism. The emotional costs of globalization. London: Routledge.

Erickson, M. (1967). Laboratory and clinical hypnosis: The same or different phenomena? American Journal of Clinica Hypnosis, 9, 166-170.

Erickson, M. (1986). Healing in hypnosis. New York, NY: Irvington.

Erickson, M. (1992). Creative choices in bypnosis. New York: Irvington.

Erickson, M., \& Rossi, E. (1979). Hypnotherapy: An exploratory casebook. New York, NY: Irvington.

Ferro, A., \& Basille, R. (2015). Le champ analytique. Montreuil: Ithaque.

Gallagher, S. (2012). Multiple aspects of agency. New Ideas in Psychology, 30, 15-31. doi: 10.1016/j. newideapsych.2013.03.003.

Gonzalez Rey, F. (2003). Sujeito e subjetividade. São Paulo: Thomsom.

Gonzalez Rey, F. (2005). Pesquisa qualitativa e subjetividade. São Paulo: Thomsom.

Gonzalez Rey, F. (2011). Subjetividade e saúde. São Paulo: Cortez.

Hall, S. (2014). A identidade cultural na pós-modernidade. São Paulo: Lamparina.

Hennink, M., Hutter, I., \& Bailey, A. (2011). Qualitative research methods. Los Angeles: Sage Publications. 
Jensen, M., \& Patterson, D. (2014). Hypnotic approaches for chronic pain management. American Psychologist, 2, 167-177. doi: 10.1037/a0035644.

Kim, J. H. (2015). Understanding narrative inquiry. London: Sage Publications.

Leiris, M. (1980). La possession et ses aspects théatraux chez les éthiopiens de Gondar. Paris: Le Sycomore.

Lévy, A. (1997). Sciences cliniques et organisations sociales. Paris: Puf.

Lewin, K. (1964). Field theory in social science. New York: Harper Torchbooks.

Michaux, D. (2007). Hypnose et douleur. Paris: Imago.

Morin, E. (1996). A noção de sujeito. Em D. FriedSchnitman (Eds.). Novos paradigmas, cultura $e$ subjetividade. (J. Rodrigues, Trad). (pp. 45-58). Porto Alegre: Artmed.

Morin, E. (2001). La méthode V. L'bumanité de l'bumanité. Paris: Seuil.

Morin, E. (2015). Penser global. Paris: Ed Robert Laffont.

Nathan, T. (2007). À qui j'appartiens? Écrits sur la psychothérapie, sur la guerre et sur la paix. Paris: Seuil/ Synthélabo.

Nathan, T. (2015). Quand les dieux sont en guerre. Paris: La Découverte.

Neubern, M. (2004). Complexidade e psicologia clínica. Brasília: Plano.

Neubern, M. (2012a). Drama como proposta de compreensão da clínica de Milton Erickson. Interação em Psicologia, 16(2), 307-315. doi: 105380/psi. v16i2.25294

Neubern, M. (2012b). Prática social, hipnose e dor crônica: Alternativas de compreensão.
Psicologia em Estudo, 17(4), 597-606. doi: 10.1590 / S1413-73722012000400006

Neubern, M. (2013a). Psicoterapia e espiritualidade. Belo Horizonte: Diamante.

Neubern, M. (2013b). Hipnose, dores crônicas e técnicas de ancoragem. A terapia de dentro para fora. Psicologia: Teoria \& Pesquisa, 29(3), 297-304. doi: 10.1590/S0102-37722013000300007

Neubern, M. (2014). Subjetividade e complexidade na clínica psicológica: Superando dicotomias. Fractal, Revista de Psicologia, (26)3, 835-852. doi: 10.1590/1984-0292/971

Ribeiro, J. (2007). O ciclo do contato. São Paulo: Summus.

Riessman, C. (2008). Narrative methods for the buman sciences. London: Sage Publications.

Roustang, F. (2015). Jamais contre, d'abord. La présence d'un corps. Paris: Odile Jacob.

Santos, B. (2000). A crítica da razãa indolente. São Paulo: Cortez.

Sardan, J. P. (2015). La rigueur du qualitatif. Louvain: Academia-Bruylant.

Scheschner, R. (2013). Performance studies. An introduction. London: Routledge.

Stengers, I. (2001a). Qu'est-ce que l'hypnose nous oblige à penser? Ethnopsy, 3, 13-68.

Stengers, I. (2001b). Préface. Le laboratoire de l'ethnopsychiatre. Em T. Nathan. Nous ne sommes pas seuls au monde. (pp. 7-46). Paris: Seuil/Synthélabo.

Recebido em: 01/02/2016

Reformulado em: 02/06/2016 Aceito em: 16/06/2016 
Sobre o autor:

Maurício S. Neubern é doutor em Psicologia, professor adjunto do Instituto de Psicologia, Universidade de Brasília (UnB), coordena o Projeto CHYS (Complexidade, Hypnose e Subjetividade), onde desenvolve pesquisa, ensino e extensão em torno da hipnose, principalmente para pessoas com dores crônicas. Esse tópico foi aprofundado em seu pós-doutorado, do qual deriva o presente artigo, realizado no Centre Edgar Morin, École des Hautes Études en Sciences Sociales, Paris, França (financiado pela CAPES 2015/2016).

E-mail: mauricio.neubern@gmail.com

\section{Contato com o autor:}

Instituto de Psicologia, Departamento de Psicologia Clínica

Campus Darcy Ribeiro, ICC Sul

Asa Norte, Brasília-DF, Brasil

CEP: 70910-900

Fone: (61) 3107-6890 